\title{
Research on the key technology of the personalized English learning system

\author{
LIANG Yuan ${ }^{1, a}$ \\ ${ }^{1}$ Jilin Business and Technology College, Changchun 130062, China \\ aLiangYuan1026@yeah.net
}

Keywords: Individualized; English learning; system design

\begin{abstract}
The lack of language learning environment which caused low teaching efficiency has plagued many foreign language teachers for many years. So this paper design a high efficiency English learning system at a low cost to Guide the reform of English teaching system and to improve the efficiency of English teaching. The design uses AI and Internet technology, simulating the actual life, to construct and share multimedia language teaching environment. This paper prove and design an intelligent and innovative English learning system, and Make a detailed planning for function realization.
\end{abstract}

\section{The characteristics and function of intelligent English learning system}

In the teaching practice, this paper analyzes the weak link of Chinese students learning English in the current situation, and forward-looking proposed the function intelligent English learning system should have based on the direction of the development of computer network English learning system and the level of development of artificial intelligence technology such as speech recognition and natural language recognition.

\section{The function of intelligent English learning system}

The purpose of design of the system is to use the advanced information technology to promote the teaching of English listening based on the Internet. It is helpful for students to master their own learning time and environment, which is good to cultivate students' autonomous learning ability through the help of teachers.

The characteristics of Intelligent interactive English learning system is "give grade test-give score-find out the problem-give targeted exercises- repeat exercises". According to the different scores and results, the system will give different practice of speech sounds, listening, reading, writing and translation. This system emphasizes on intelligence and initiative to do individualized teaching.

\section{The characteristics of intelligent English learning system}

I. Have a wide user coverage

This system will adapt to various of industry to satisfy different user's requirements such as tourism English and business English.

II. The training method is entertainment

The system uses games and animation to design training exercises to make learning interesting. It emphasize interest and humanization.

III. Simulate the actual life scenes

Training and test material should be as close as possible to the actual life, selecting learning materials in student's daily life.

IV. Learn from the various points and hence

It is necessary to have a multi-angle study on the same theme. For example, for a difficult subject, do reading, translation, hearing and speech training and testing one by one step. 
V. Pay attention to the use of correcting repeated training

If a student didn't get a high score in a practice but just pass the pass a test, according to the requirements of cognitive law "Repetition is the basis of language learning", he should do some follow-up study. The system will repeat the correcting questions for many times, till the student get "A" twice.

VI. Have a standardized classification

Grading standard system should link some pass exams, such as TOFEL, GRE, C'ET4, C'ET6 and Interpretation test, to give student a cross reference between the level of training and examination grades.

\section{The design of intelligent English learning system}

\section{Get and deal with resources}

The main starting point of the construction of the whole system is that the users can query and read the example words and sentences through the system. This needs to build a rich English words resources library. The resource requirements is to construct thesaurus and audio resources library based on different levels of difficulty levels (such as "new-concept level", "CET-4 level" and "CET-6 level"). The process of getting resources is shown as follows.

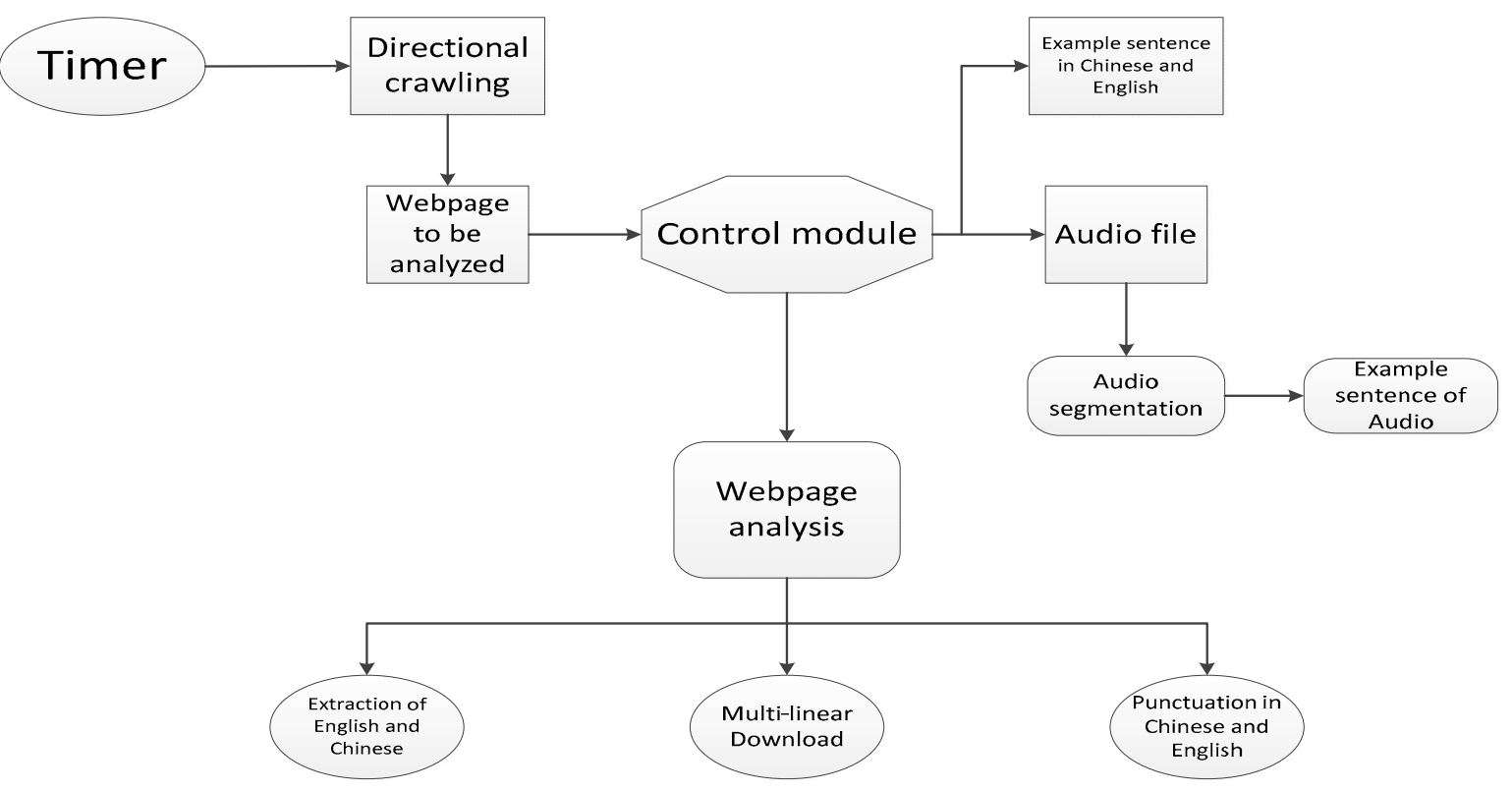

Figure1. Progress of Resource Acquisition

In order to meet the demand of resources, taking the full use of the Internet resources into account, it can be divided into two levels in the resources construction. Firstly, the coverage of vocabulary words should be ensured. And secondly, the text covering each difficulty level and type should be ensured. After the stipulated two level, it need to design different resources obtain strategies.

First of all, for the construction of the first demand, we should design a method of resource acquisition. The core of strategy we take is to use some of the vertical search engines, taking the word as a query term for example access and extracting the corresponding English and Chinese by Webpage analytical technique. It should be pointed out that it relates to the download of audio example, which is different from traditional Webpage downloading. So that we adopted a divide and conquer strategy in Webpage resolution: the texts and audios are separately downloaded. In Webpage resolution, only the corresponding URL address of the audio need to be extracted.

After the access to resources, the system should evaluate the quality of resources, the evaluation process is shown in the figure 2 . 


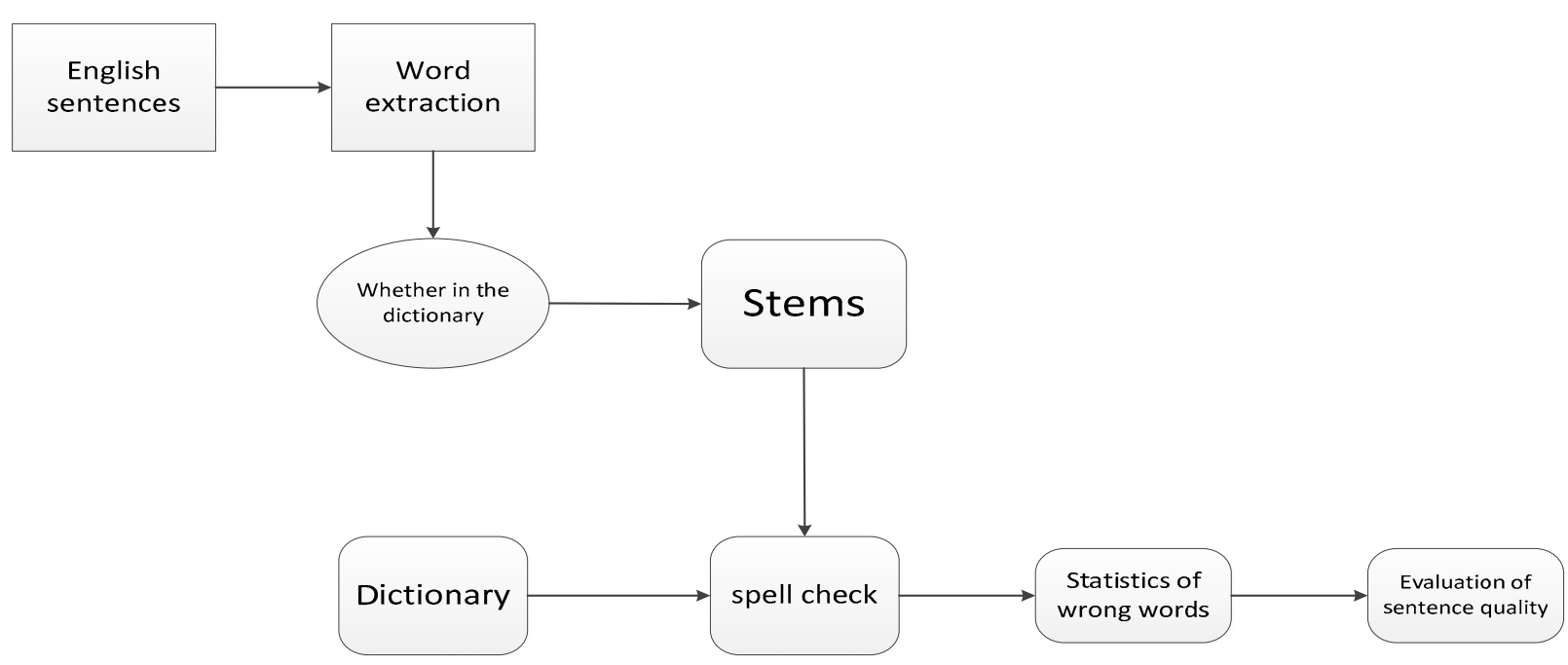

Figure2. Test Quality Evaluation

\section{The local retrieval system based on mobile platform}

This mobile terminal system will be based on the IOS mobile platform, which has a low level of storage capacity and computing ability. As to the weakness of IOS platform, this system will use effective countermeasures to optimize local retrieval system and space and time performance to satisfied users.

\section{The realization of the system}

The module of system includes:
A. text retrieval module;
B. automatic prompt module;
C. audio player module;
D. thesaurus browsing module;
E. user's history module.

According to the previously proposed requirements and the corresponding algorithm, the author do some programming work, the overall system architecture is shown in figure 3.

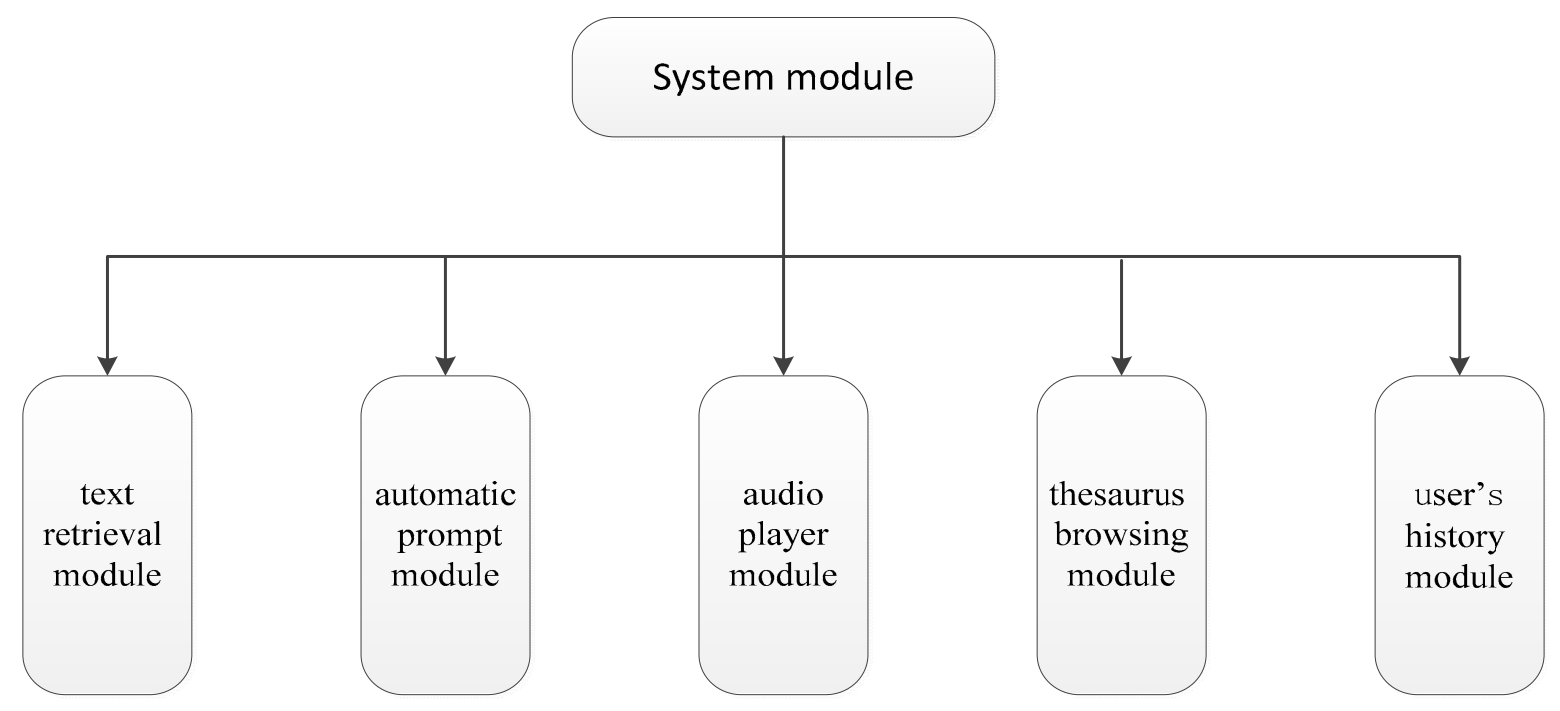

Figure3. Structure of System

\section{Conclusion}

There are three difficult points of realization of personalized English learning system project:(1)the 
intelligent level is limited; (2)this system is an innovative concept, which has no experience to follow; (3)there isn't ready-made theories on language teaching and testing, we should do lots of work before develop the system.

In the development process, the author adheres to three principles: firstly, the system focus on its own advantages and characteristics; secondly, this system controls problems by using step-by-step. It can make the developer find the problem at the beginning and control and deal with it. Thirdly, if some advanced features is difficult to achieve, the developer can reduce the requirements and purchase mature technology patents and the access to language resources to shorten the development time of the project.

\section{References}

[1]Chen C M, Hsu S H, Li Y L, et al. Personalized intelligent m-learning system for supporting effective English learning[C]//Systems, Man and Cybernetics, 2006. SMC'06. IEEE International Conference on. IEEE, 2006, 6: 4898-4903.

[2]Chan T W, Roschelle J, Hsi S, et al. One-to-one technology-enhanced learning: An opportunity for global research collaboration[J]. Research and Practice in Technology Enhanced Learning, 2006, 1: 3-29.

[3]Ali R, Irvine V. Current m-learning research: A review of key literature[C]//World Conference on E-Learning in Corporate, Government, Healthcare, and Higher Education. 2009, 2009(1): 2353-2359.

[4]Salmon G. E-moderating: The key to teaching and learning online[M]. Psychology Press, 2004.

[5]Shee D Y, Wang Y S. Multi-criteria evaluation of the web-based e-learning system: A methodology based on learner satisfaction and its applications[J]. Computers \& Education, 2008, 50(3): 894-905. 